\title{
Association Between IL-6 and Seizure Recurrence in Patients with the First Post-Ischemic Stroke Seizure
}

This article was published in the following Dove Press journal: Neuropsychiatric Disease and Treatment

\author{
Qi Jia' \\ Fan Jiang ${ }^{2}$ \\ Daliang Ma' \\ Jun $\mathrm{Li}^{1}$ \\ Fan Wang' \\ Zhiqiang Wang' \\ 'Encephalopathy Center, The Third \\ People's Hospital of Xinjiang Uygur \\ Autonomous Region, Urumqi 830000, \\ People's Republic of China; ${ }^{2}$ Neonatal \\ Intensive Care Unit, The First People's \\ Hospital of Urumqi, Urumqi 830000, \\ People's Republic of China
} acteristic (ROC) curve.
Correspondence: Zhiqiang Wang Encephalopathy Center, The Third People's Hospital of Xinjiang Uygur Autonomous Region, No. 168, Nanchang Road, Urumqi 830000, People's Republic of China

$\mathrm{Tel} / \mathrm{Fax}+86-9917530284$

Email xjwjwzq@I63.com
Purpose: To study the association between IL-6 level and seizure recurrence in patients with the first post-ischemic stroke seizure and assess its predictive value for seizure recurrence.

Patients and Methods: A total of 2976 consecutive ischemic stroke patients were retrospectively enrolled. Among them, 209 (7.02\%) patients with the first post-ischemic stroke seizure were included in this analysis. The IL-6 mRNA expression level was evaluated through quantitative real-time PCR (qRT-PCR) and the $2^{-\Delta \Delta C t}$ method. Demographic data and clinical characteristics were collected. Univariate analysis was performed with independent-samples $t$-test, Mann-Whitney $U$-test, or chi-square test. Multivariate analysis was conducted using a backward stepwise logistic regression model for variables with $P<0.10$ in univariate analysis. The predictive value was assessed using a receiver operating char-

Results: Among the patients included, 105 (50.24\%) had recurrence of seizures, and 104 $(49.76 \%)$ had no recurrence. Multivariate analysis demonstrated that the IL-6 mRNA expression level was independently correlated with seizure recurrence in patients with the first post-ischemic stroke seizure after adjusting for age, NIHSS scores, time of seizure, seizure type, lesion size, location of the offending lesion to different hemispheric lobes, cortical involvement, gender, electroencephalography (EEG) findings, and hemorrhagic transformation. When the IL- 6 mRNA expression level was used to predict seizure recurrence, the area under the ROC curve (AUC) was 0.763 ( $\mathrm{SE}=0.033,95 \% \mathrm{CI}=0.698-0.829$ ). The diagnostic power was moderate.

Conclusion: IL-6 was independently correlated with seizure recurrence in patients with the first post-ischemic stroke seizure and might be a potential biomarker for prediction of seizure recurrence.

Keywords: post-ischemic stroke seizure, seizure recurrence, IL-6, predictive value

\section{Introduction}

Epilepsy is a complex, multifactorial neurological disease, which is mainly characterized by a predisposition to seizure recurrence. ${ }^{1}$ About 70 million people are affected by epilepsy all over the world, and one third of them are never free of seizures even when they receive a therapy employing anti-epileptic drugs. ${ }^{2}$ Ischemic stroke is an important cause of epilepsy, especially in elderly people. ${ }^{3}$ In the last decades, the incidence of post-stroke epilepsy has increased due to important advances in the therapeutic management of stroke that have reduced its mortality rate in the acute phase. ${ }^{4,5}$ A recent investigation reported that the 
incidence of post-stroke seizures could reach $15.3 \%{ }^{6}$ After stroke, epilepsy can threaten patients not only through potential physical injuries, but also through deleterious effects on the brain with stroke lesion and degenerative changes. ${ }^{7}$ In addition, recurrent peri-infarct depolarization may harm already vulnerable tissues through further neuronal injuries caused by the additional metabolic stress. ${ }^{8,9}$ Epilepsy after stroke has been demonstrated to be associated with decreased survival at 30-day and 1-year time points as well as increased length of hospital stay and resource utilization. ${ }^{10,12}$ The importance of post-stroke epilepsy also contemplates cognitive functioning, a lower disease-specific quality-of-life, and more disability and neurological impairment. ${ }^{13}$ Therefore, prediction and management of seizure recurrence is critical for stroke care. However, other studies did not observe any association between post-stroke seizures and long-term disability/mortality. ${ }^{14,15}$

Inflammation induced by the ischemic cerebrovascular process participates in the initiation and continuation of seizures. $^{16,18}$ Interleukin-6 (IL-6) is a pro-inflammatory cytokine and associated with cardiovascular diseases, ${ }^{19,22}$ suggesting its critical role in the inflammatory response to cerebral ischemia. ${ }^{23}$ In addition, studies show that IL-6 is associated with development of seizures. ${ }^{24,26}$ Elevated IL-6 levels are confirmed in several different epilepsy etiologies and media. ${ }^{27}$ However, no previous studies investigated the association between IL-6 levels and seizure recurrence in patients with the first post-ischemic stroke seizure and its value in predicting seizure recurrence. In this study, we performed the above investigation with the aim of providing a basis for clinicians to predict seizure recurrence.

\section{Patients and Methods}

\section{Included Patients}

Between March 2013 and March 2018, 2976 consecutive ischemic stroke patients were retrospectively enrolled in the Third People's Hospital of Xinjiang Uygur Autonomous Region. Among them, 209 (7.02\%) patients were diagnosed with post-stroke seizure and included in this study. Data were obtained through reviewing medical records of their routine care for ischemic stroke and seizure at outpatient department visits and admission. Seizure recurrence was followed up by neurologists in all participants until March 2019. This study was conducted in accordance with the Declaration of Helsinki and received the approval of the ethics committee of the Third People's Hospital of
Xinjiang Uygur Autonomous Region (20130241018), and each participant provided written informed consent.

\section{Inclusion and Exclusion Criteria of Included Patients}

Inclusion criteria included 1) patients with first-ever ischemic stroke which was definitely diagnosed through signs and symptoms, magnetic resonance imaging (MRI), or computed tomography (CT) findings, and medical histories; 2) patients with the first post-ischemic stroke seizure which was determined based on the definition described by Fisher et al; ${ }^{28} 3$ ) complete medical records; and 4) informed consent. Exclusion criteria included 1) patients with potential epileptogenic lesions, such as cerebral vascular malformation, cerebral hemorrhage, brain tumor, traumatic brain injury, and cortical dysplasia; 2) patients with a family history of epilepsy or patients previously diagnosed with epilepsy; and 3) patients with transient ischemic attack (TIA).

\section{Key Definitions}

Early onset was defined as the first post-ischemic stroke seizure occurring within 1 week after stroke insult and late onset as occurring outside 1 week. Seizure recurrence referred to the second unprovoked and separated seizure from the first one by $>24$ hours. Standard EEG of 20-30 minutes duration was conducted in all 209 patients within 24-72 hours of the first post-ischemic stroke seizure onset. Abnormal EEG findings included epileptiform discharge, generalized slow, and regional slow. Partial seizures were defined as originating within networks limited to one hemisphere, and generalized seizures were defined as originating at some point within, and quickly involving, bilaterally distributed networks.

\section{Detection of the IL-6 mRNA Expression Level}

The blood samples were collected after acute ischemic stroke (AIS) in all 209 patients. Total RNA was extracted from blood samples through the miRCURY ${ }^{\mathrm{TM}}$ RNA Isolation kit for Biofluids (Exiqon, Vedbaek, Denmark). cDNA was then synthesized with the miRCURY LNA Universal cDNA Synthesis Kit II (Exiqon, Vedbaek, Denmark). Quantitative Real-Time PCR (qRT-PCR) was performed with the RotorGene $^{\circledR}$ Q Real-Time Fluorescence Quantitative PCR Analyzer (Qiagen, Germany). The $2^{-\Delta \Delta \mathrm{Ct}}$ method was employed to assess the IL-6 mRNA expression level using 
GADPH as a reference gene. The primer sequences of IL-6 were 5'-ATCAGGAGACCTGCTTGATG-3' (sense) and 5'TGGTGGCTTTGTCTGGATTC-3' (anti-sense), and the primer sequences of GADPH were 5'-AGCCTCAAGATCA GCAATG-3' (sense) and 5'-CACGATACCAAAGTTGTC ATGGAT-3' (anti-sense).

\section{Statistical Analysis}

All data were statistically analyzed through the SPSS version 19.0 for Windows (SPSS Inc., USA), and significance was set at $P<0.05$. Continuous data were validated for normality with Kolmogorov-Smirnov test. Normal data were demonstrated as mean \pm standard deviation (SD), and independent-samples $t$-test was used to perform univariate analysis; and non-normal data were demonstrated as median and interquartile range, and Mann-Whitney $U$-test was used to perform univariate analysis. Categorical data were demonstrated as ratios or percentages (\%), and chi-square test was used to perform univariate analysis. Multivariate analysis was then conducted using a backward stepwise logistic regression model for variables with $P<0.10$ in univariate analysis. Among the variables included in multivariate analysis, age was a continuous variable, grades of the IL-6 mRNA expression level, NIHSS scores, and lesion size were multicategorical variables, and time of seizure, seizure type, cortical involvement, gender, EEG findings, and hemorrhagic transformation were binary variables. The predictive value was assessed using a receiver operating characteristic (ROC) curve.

\section{Results}

\section{Demographic Data and Clinical Characteristics}

All 209 patients with the first post-ischemic stroke seizure included 117 (55.98\%) males and 92 (44.02\%) females. Their average age was $62.93 \pm 8.82$ years, ranging from 37-82 years. Among them, 105 (50.24\%) patients had recurrence of seizures (case group) and 104 (49.76\%) patients had no recurrence (control group). The detailed demographic data and clinical characteristics are shown in Table 1. According to univariate analysis (Table 1), age, NIHSS scores, time of seizure, seizure type, lesion size, location of the offending lesion to different hemispheric lobes, and cortical involvement were statistically different between case group and control group $(P<0.05)$, and the remaining variables were not statistically different $(P>0.05)$.

\section{IL-6 mRNA Expression Level}

The average expression level of IL-6 mRNA was 4.87 \pm 1.91 for all 209 patients with the first post-ischemic stroke seizure, and the expression level was higher in the case group than in the control group $(6.32 \pm 2.18$ vs 3.41 $\pm 1.64, t=10.912, P<0.001)$. The expression level were then classified into four grades according to the quartiles (Q1, Q2, and Q3) of the control group. Chi-square test also demonstrated that the expression level was higher in case group than in control group (Table 2).

\section{Multivariate Analysis}

Grades of the IL-6 mRNA expression level, age, NIHSS scores, time of seizure, seizure type, lesion size, location of the offending lesion to different hemispheric lobes, cortical involvement, gender, EEG findings, and hemorrhagic transformation were included in multivariate analysis. Multivariate analysis demonstrated that the IL-6 mRNA expression level was independently correlated with seizure recurrence in patients with the first postischemic stroke seizure after adjusting for age, NIHSS scores, time of seizure, seizure type, lesion size, location of the offending lesion to different hemispheric lobes, cortical involvement, gender, EEG findings, and hemorrhagic transformation (Table 3).

\section{ROC Analysis}

As shown in Figure 1, when grades of the IL-6 mRNA expression level was used to predict seizure recurrence in patients with the first post-ischemic stroke seizure, the area under the ROC curve (AUC) was 0.763 ( $\mathrm{SE}=0.033,95 \%$ $\mathrm{CI}=0.698-0.829$ ), and the AUC adding IL-6 to the other independent variables associated with seizure recurrence was $0.820(\mathrm{SE}=0.029,95 \% \mathrm{CI}=0.762-0.877)$. When the IL-6 mRNA expression level $>$ Q3 (5.27) was used as the diagnosis criterion, the diagnosis results are shown in Table 4. The AUC was $0.718 \quad(\mathrm{SE}=0.036, \quad 95 \%$ $\mathrm{CI}=0.647-0.788$ ). The sensitivity, specificity, accuracy, false positive rate, false negative rate, positive predictive value, and negative predictive value were $68.57 \%, 75.00 \%$, $71.77 \%, 26.53 \%, 29.73 \%, 73.47 \%$, and $70.27 \%$, respectively. Therefore, its diagnostic power was moderate.

\section{Discussion}

Inflammation after ischemic stroke is an unavoidable pathological process associated with post-ischemic injury in the brain. ${ }^{29,30}$ Peripheral and central inflammation can 
Table I Demographic Data and Clinical Characteristics of Case Group and Control Group

\begin{tabular}{|c|c|c|c|c|c|}
\hline & & $\begin{array}{l}\text { Case Group } \\
(n=105)\end{array}$ & $\begin{array}{l}\text { Control Group } \\
(n=104)\end{array}$ & $\chi^{2} / Z / t$ & $\boldsymbol{P}$ \\
\hline Male (n, \%) & & 65 (6I.90\%) & $52(50.00 \%)$ & 3.005 & 0.083 \\
\hline Age (years) & & $60.92 \pm 7.91$ & $64.96 \pm 9.74$ & 3.29 & 0.002 \\
\hline Nationalities (n, \%) & $\begin{array}{l}\text { Han } \\
\text { Uygur } \\
\text { Other }\end{array}$ & $\begin{array}{l}53(50.48 \%) \\
39(37.14 \%) \\
13(12.38 \%)\end{array}$ & $\begin{array}{l}48(46.15 \%) \\
42(40.38 \%) \\
14(13.46 \%)\end{array}$ & 0.391 & 0.822 \\
\hline Educational level (n, \%) & $\begin{array}{l}\text { Primary school and below } \\
\text { Junior high school } \\
\text { Senior high school and above }\end{array}$ & $\begin{array}{l}26(24.76 \%) \\
45(42.86 \%) \\
34(32.38 \%)\end{array}$ & $\begin{array}{l}29(27.88 \%) \\
44(42.31 \%) \\
31(29.81 \%)\end{array}$ & 0.309 & 0.857 \\
\hline Annual family income (RMB) (n, \%) & $\begin{array}{l}<10,000 \\
10,000-20,000 \\
>20,000\end{array}$ & $\begin{array}{l}24(22.86 \%) \\
4 I(39.05 \%) \\
45(42.86 \%)\end{array}$ & $\begin{array}{l}21(20.19 \%) \\
45(43.27 \%) \\
48(46.15 \%)\end{array}$ & 0.412 & $0.8 \mid 4$ \\
\hline Occupation (n, \%) & $\begin{array}{l}\text { Farmer } \\
\text { Worker } \\
\text { Civil servant/teacher/doctor }\end{array}$ & $\begin{array}{l}36(34.29 \%) \\
39(37.14 \%) \\
30(28.57 \%)\end{array}$ & $\begin{array}{l}40(38.46 \%) \\
35(33.65 \%) \\
29(27.88 \%)\end{array}$ & 0.439 & 0.803 \\
\hline $\begin{array}{l}\text { Smoking }(n, \%) \\
\text { Drinking (n, \%) } \\
\text { Diabetes mellitus (n, \%) } \\
\text { Hypertension (n, \%) } \\
\text { Coronary heart disease (n, \%) } \\
\text { Atrial fibrillation (n, \%) }\end{array}$ & & $\begin{array}{l}33(31.43 \%) \\
22(20.95 \%) \\
18(17.14 \%) \\
69(65.71 \%) \\
38(36.19 \%) \\
16(15.24 \%)\end{array}$ & $\begin{array}{l}30(28.85 \%) \\
25(24.04 \%) \\
14(13.46 \%) \\
60(57.69 \%) \\
43(41.35 \%) \\
11(10.58 \%)\end{array}$ & $\begin{array}{l}0.165 \\
0.285 \\
0.546 \\
1.423 \\
0.585 \\
1.009\end{array}$ & $\begin{array}{l}0.684 \\
0.593 \\
0.46 \\
0.233 \\
0.444 \\
0.315\end{array}$ \\
\hline TOAST classification $(\mathrm{n}, \%)$ & $\begin{array}{l}\text { Large artery atherosclerosis } \\
\text { Cardioembolism } \\
\text { Small vessel } \\
\text { occlusion } \\
\text { Other determined } \\
\text { Undetermined }\end{array}$ & $\begin{array}{l}49(46.67 \%) \\
24(22.86 \%) \\
12(11.43 \%) \\
2(1.90 \%) \\
18(17.14 \%)\end{array}$ & $\begin{array}{l}52(50.00 \%) \\
19(18.27 \%) \\
15(14.42 \%) \\
2(1.92 \%) \\
16(15.38 \%)\end{array}$ & & $0.897^{*}$ \\
\hline NIHSS scores (n, \%) & $\begin{array}{l}\text { Mild }(\leq 8) \\
\text { Moderate }(9-15) \\
\text { Severe }(\geq 16)\end{array}$ & $\begin{array}{l}34(32.38 \%) \\
42(40.00 \%) \\
29(27.62 \%)\end{array}$ & $\begin{array}{l}51(49.04 \%) \\
39(37.50 \%) \\
14(13.46 \%)\end{array}$ & 8.739 & 0.013 \\
\hline $\begin{array}{l}\text { Total cholesterol }(\mathrm{mmol} / \mathrm{L}) \\
\text { Triacylglycerol }(\mathrm{mmol} / \mathrm{L}) \\
\text { Low density lipoprotein cholesterol }(\mathrm{mmol} / \mathrm{L}) \\
\text { High density lipoprotein cholesterol }(\mathrm{mmol} / \mathrm{L}) \\
\text { Status epilepticus }(\mathrm{n}, \%)\end{array}$ & & $\begin{array}{l}4.8 I \pm 1.05 \\
I .4 I \pm 0.75 \\
3.12 \pm 0.96 \\
0.97 \pm 0.42 \\
10(9.52 \%)\end{array}$ & $\begin{array}{l}4.62 \pm 0.89 \\
1.33 \pm 0.60 \\
2.94 \pm 0.58 \\
1.06 \pm 0.57 \\
7(6.73 \%)\end{array}$ & $\begin{array}{l}1.412 \\
0.852 \\
1.642 \\
1.298 \\
0.545\end{array}$ & $\begin{array}{l}0.158 \\
0.406 \\
0.132 \\
0.174 \\
0.614\end{array}$ \\
\hline Time of seizure $(n, \%)$ & $\begin{array}{l}\text { Early onset } \\
\text { Late onset }\end{array}$ & $\begin{array}{l}4 \mathrm{I}(39.05 \%) \\
64(60.95 \%)\end{array}$ & $\begin{array}{l}58 \text { (55.77\%) } \\
46(44.23 \%)\end{array}$ & 5.86 & 0.019 \\
\hline Seizure type (n, \%) & $\begin{array}{l}\text { Generalized } \\
\text { Partial }\end{array}$ & $\begin{array}{l}46(43.81 \%) \\
59(56.19 \%)\end{array}$ & $\begin{array}{l}61(58.65 \%) \\
43(41.35 \%)\end{array}$ & 4.608 & 0.032 \\
\hline EEG findings (n, \%) & $\begin{array}{l}\text { Normal } \\
\text { Abnormal }\end{array}$ & $\begin{array}{l}47 \text { (44.76\%) } \\
58 \text { (55.24\%) }\end{array}$ & $\begin{array}{l}60(57.69 \%) \\
44(42.31 \%)\end{array}$ & 3.496 & 0.062 \\
\hline Lesion size $(\mathrm{n}, \%)$ & $\begin{array}{l}\text { Small } \\
\text { Moderate } \\
\text { Large }\end{array}$ & $\begin{array}{l}12(11.43 \%) \\
31(29.52 \%) \\
62(59.05 \%)\end{array}$ & $\begin{array}{l}28(26.92 \%) \\
30(28.85 \%) \\
46(44.23 \%)\end{array}$ & 8.782 & 0.012 \\
\hline
\end{tabular}

(Continued) 
Table I (Continued).

\begin{tabular}{|c|c|c|c|c|c|}
\hline & & $\begin{array}{l}\text { Case Group } \\
(n=105)\end{array}$ & $\begin{array}{l}\text { Control Group } \\
(n=104)\end{array}$ & $\chi^{2} / Z / t$ & $P$ \\
\hline Lesion location (n, \%) & $\begin{array}{l}\text { Anterior infarct } \\
\text { Posterior infarct }\end{array}$ & $\begin{array}{l}83(79.05 \%) \\
22(20.95 \%)\end{array}$ & $\begin{array}{l}76(73.08 \%) \\
28(26.92 \%)\end{array}$ & 1.023 & 0.313 \\
\hline $\begin{array}{l}\text { Location of the offending lesion to different } \\
\text { hemispheric lobes }(n, \%)\end{array}$ & $\begin{array}{l}\text { Temporal lobes } \\
\text { Frontal lobes } \\
\text { Parietal lobes } \\
\text { Occipital lobes } \\
\text { Basal ganglia } \\
\text { Thalamus }\end{array}$ & $\begin{array}{l}43(40.95 \%) \\
4 I(39.05 \%) \\
37(35.24 \%) \\
34(32.38 \%) \\
28(26.67 \%) \\
20(19.05 \%)\end{array}$ & $\begin{array}{l}26(25.00 \%) \\
24(23.08 \%) \\
26(25.00 \%) \\
27(25.96 \%) \\
24(23.08 \%) \\
18(17.31 \%)\end{array}$ & $\begin{array}{l}6.012 \\
6.219 \\
2.601 \\
1.042 \\
0.360 \\
0.106\end{array}$ & $\begin{array}{l}0.014 \\
0.013 \\
0.109 \\
0.307 \\
0.548 \\
0.744\end{array}$ \\
\hline $\begin{array}{l}\text { Reperfusion therapy (n, \%) } \\
\text { Antiepileptic drugs (n, \%) } \\
\text { Hemorrhagic transformation (n, \%) } \\
\text { Cortical involvement (n, \%) }\end{array}$ & & $\begin{array}{l}35(33.33 \%) \\
97(92.38 \%) \\
30(28.57 \%) \\
46(43.81 \%)\end{array}$ & $\begin{array}{l}25(24.04 \%) \\
101(97.12 \%) \\
19(18.27 \%) \\
29(27.88 \%)\end{array}$ & $\begin{array}{l}2.206 \\
2.349 \\
3.09 \\
5.759\end{array}$ & $\begin{array}{l}0.138 \\
0.125 \\
0.079 \\
0.016\end{array}$ \\
\hline
\end{tabular}

Notes: Lesion size: large ( $>50 \times 50 \mathrm{~mm}$ and $>5$ slices), moderate $(\leq 15 \times 15 \mathrm{~mm}$ and $>5$ slices or $>50 \times 50 \mathrm{~mm}$ and $\leq 5$ slices) and small $(\leq 15 \times 15 \mathrm{~mm}$ and $\leq 5$ slices). $*$ Fisher's Exact Test.

Abbreviations: TOAST, trial of org 10172 in acute stroke treatment; EEG, electroencephalography.

contribute to damage of the blood-brain barrier through upregulating inflammatory mediators. On the other hand, persistent inflammation can affect neuronal plasticity with network reorganization through several transcriptionally modulated mechanisms, which is potentially associated with aberrant and epileptogenic circuits. ${ }^{31,35}$ Seizures are well-acknowledged complications following ischemic stroke. ${ }^{36,37}$ Although their exact mechanism remains unknown, neurologic inflammation and damage to the blood-brain barrier are demonstrated indispensable components of epileptogenesis after brain injury. ${ }^{38}$ Several inflammatory cytokines, such as IL-6, IL- $1 \beta$, etc., have been detected in human epileptogenic tissue and cerebrospinal fluid, and, meanwhile, they have also been shown as involvements in the initiation and continuation of seizures through experimental models.

IL-6 is a pro-inflammatory cytokine and its levels are low in the central nervous system under normal conditions.

Table 2 Number of Patients in Four Grades of the IL-6 mRNA Expression Level

\begin{tabular}{|l|l|l|l|l|}
\hline & $\begin{array}{l}\text { Case } \\
\text { Group } \\
(\mathbf{n}=105)\end{array}$ & $\begin{array}{l}\text { Control } \\
\text { Group } \\
(\mathbf{n}=104)\end{array}$ & $\chi^{2}$ & $P$ \\
\hline Grade I [ $\leq \mathrm{Q}$ I (I.82)] & 3 & 26 & 49.692 & $<0.001$ \\
Grade 2 [>Q1 and $\leq \mathrm{Q} 2(3.53)]$ & 8 & 26 & & \\
Grade 3 [>Q2 and $\leq \mathrm{Q} 3(5.27)]$ & 22 & 26 & & \\
Grade 4 (>Q3) & 72 & 26 & & \\
\hline
\end{tabular}

However, its levels elevate significantly in many diseases, for example, stroke, epilepsy, brain damage, and so on. ${ }^{39,40}$ During brain inflammation, IL-6 is primarily secreted by glial cells. ${ }^{41}$ Stimulation of microglia and astrocytes may result in increased secretion of IL- $6 .{ }^{42}$ In addition, elevated levels of other inflammatory cytokines, such as IL-1 $\beta$, IL-17, $\mathrm{TNF}-\alpha$, etc., can also upregulate the expression of IL- $6 .{ }^{43}$ Fang et $\mathrm{al}^{44}$ demonstrated that IL- 6 could inhibit neuronal necrosis and apoptosis through decreasing cytosolic $\mathrm{Ca}^{2+}$ overload induced by $\mathrm{N}$-methyl D-aspartate, implying a neuroprotection of IL-6. However, Wang et $\mathrm{al}^{45}$ found that a chronic infusion of IL- 6 could attenuate miniature excitatory postsynaptic currents regulated by $\mathrm{N}$-methyl D-aspartate receptor in the hippocampal neurons of rats treated with anti-N-methyl D-aspartate receptor, which exacerbated memory impairment of rats. Therefore, IL-6 may bidirectionally impose influence on memory and synaptic plasticity.

Upregulated IL-6 levels can not only decrease hippocampal neurogenesis and long-term potentiation (LTP) but also increase gliosis and create conditions that may contribute to the onset of epilepsy. ${ }^{43,46}$ IL- 6 can increase the blood-brain barrier permeability and has been shown as an association with development of seizures. ${ }^{24,26,47} \mathrm{Ho}$ et al ${ }^{50}$ indicate that peripheral inflammation caused by lipopolysaccharide can increase seizure susceptibility through upregulating expression of IL- 6 , IL- $1 \beta$, and TNF- $\alpha$ in the hippocampus. Erta et $\mathrm{al}^{43}$ found that transgenic IL-6 expression is pro-convulsive in mice. Samuelsson et $\mathrm{al}^{51}$ 
Table 3 Results of Multivariate Analysis

\begin{tabular}{|c|c|c|c|c|c|c|}
\hline & $\begin{array}{l}\text { Regression } \\
\text { Coefficient }\end{array}$ & $\begin{array}{l}\text { Standard } \\
\text { Error }\end{array}$ & $\begin{array}{l}\text { Wald } \\
\chi^{2}\end{array}$ & $\begin{array}{l}\text { Hazard } \\
\text { Ratio }\end{array}$ & $\begin{array}{l}95 \% \text { Confifidence } \\
\text { Interval }\end{array}$ & $P$ \\
\hline IL-6 mRNA expression level & & & 13.487 & & & $<0.00$ \\
\hline Grade 2 & 0.469 & 0.146 & 1.047 & 1.859 & $0.579-4.018$ & 0.249 \\
\hline Grade 3 & 0.743 & 0.271 & 5.118 & 4.513 & $1.414-9.122$ & 0.021 \\
\hline Grade 4 & 1.262 & 0.489 & 25.309 & 13.893 & $5.07 \mid-29.948$ & $<0.00$ \\
\hline Age & -0.506 & 0.212 & 5.285 & 0.627 & $0.413-0.914$ & 0.019 \\
\hline NIHSS scores & & & 5.442 & & & 0.015 \\
\hline Moderate & 0.632 & 0.252 & 3.925 & 1.689 & $1.159-3.376$ & 0.041 \\
\hline Severe & 1.013 & 0.494 & 7.184 & 2.249 & $1.275-4.683$ & 0.009 \\
\hline Late onset & 0.784 & 0.321 & 5.172 & 1.761 & $1.183-3.549$ & 0.021 \\
\hline Partial seizure & 0.640 & 0.283 & 5.035 & 1.686 & $1.174-3.493$ & 0.023 \\
\hline Lesion size & & & 5.821 & & & 0.013 \\
\hline Moderate & 0.645 & 0.246 & $4.14 \mid$ & 1.703 & $1.168-3.621$ & 0.037 \\
\hline Large & 1.029 & 0.448 & 7.283 & 2.312 & $1.328-3.587$ & 0.008 \\
\hline $\begin{array}{l}\text { Location of the offending lesion to different } \\
\text { hemispheric lobes }\end{array}$ & & & 4.735 & & & 0.028 \\
\hline Temporal lobes & 0.912 & 0.457 & 8.743 & 2.454 & $1.423-4.974$ & 0.004 \\
\hline Frontal lobes & 0.877 & 0.416 & 8.669 & 2.398 & $1.391-4.858$ & 0.005 \\
\hline Parietal lobes & 0.572 & 0.249 & 2.954 & 1.506 & $0.84 I-2.983$ & 0.114 \\
\hline Occipital lobes & 0.349 & 0.143 & 2.506 & 1.397 & $0.792-2.889$ & 0.158 \\
\hline Basal ganglia & 0.351 & 0.152 & 0.875 & 1.159 & $0.583-2.468$ & 0.313 \\
\hline Cortical involvement & 1.104 & 0.467 & 6.028 & 1.903 & $1.211-4.195$ & 0.011 \\
\hline Male & 0.389 & 0.151 & 1.919 & 1.398 & $0.628-2.716$ & 0.196 \\
\hline Hemorrhagic transformation & 0.467 & 0.213 & 2.575 & $\mathrm{I} .457$ & $0.830-2.782$ & 0.156 \\
\hline Abnormal EEG findings & 0.496 & 0.231 & 3.089 & 1.504 & $0.863-3.145$ & 0.123 \\
\hline
\end{tabular}

showed that prenatal exposure to IL-6 may lead to a higher risk of neurodegeneration of the hippocampus, inducing changes in both hippocampal morphology and structure. Pineda et $\mathrm{al}^{52}$ report that polyinosinic-polycytidylic acid can increase IL-6 in the offspring hippocampus through inducing maternal immune activation in experimental pregnancy, eventually resulting in faster progression of epileptogenesis and hippocampal hyperexcitability in the offspring.

In summary, IL-6 levels elevate significantly after stroke, and upregulation of IL-6 may contribute to the onset of epilepsy. In this study, the incidence of poststroke seizures was $7.02 \%$, which was basically consistent with the result of $\mathrm{Fu}$ et $\mathrm{al}^{53,54}(8.1 \%)$ and higher than Kim et al (3.3\%). Multivariate analysis demonstrated that the IL-6 level was independently correlated with seizure recurrence in patients with the first postischemic stroke seizure after adjusting for NIHSS scores and lesion size. Therefore, IL-6 does not simply mediate the association between larger/more severe AIS and recurrent seizures. In addition to IL-6, the factors associated with seizure recurrence also included age, lesion size, cortical involvement, hemorrhagic transformation, and so forth. Higher age is a protective factor, which may be correlated with smaller cerebral cortex and decreased excitability induced by degenerative changes in elderly people. ${ }^{55}$ Cortical involvement is a recognized independent risk factor, especially the temporal and frontal lobe, which may be associated with dense cortical nerve cells with a lower threshold for seizures in this region. ${ }^{56}$ The extravasation and stimulation of blood metabolites may have epileptogenic effects in the acute phase of stroke, ${ }^{57}$ and so hemorrhagic transformation is a risk factor. Large lesions usually involve the temporal and frontal lobe. ${ }^{56}$ Therefore, large lesions are also associated with seizure recurrence.

We further assessed the value of IL-6 level in predicting seizure recurrence. The results showed that the diagnostic power was moderate with sensitivity of $68.57 \%$ and specificity of $75.00 \%$. Therefore, IL-6 


\section{ROC Curve}

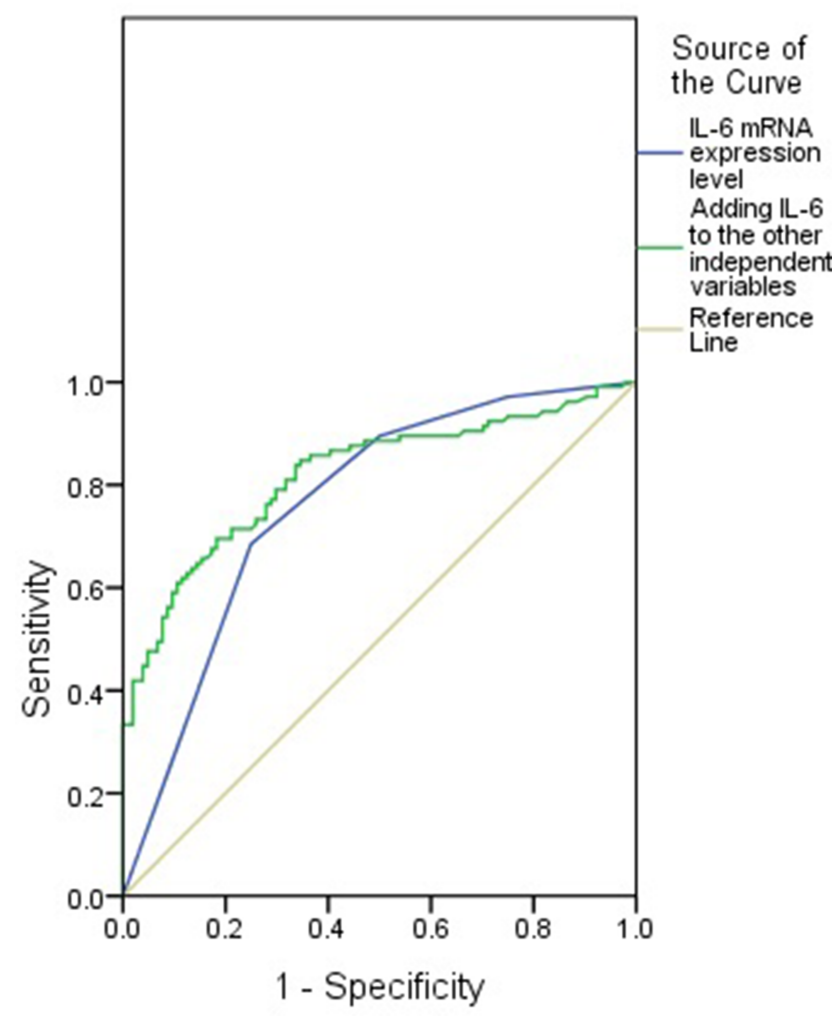

Figure I ROC curves of grades of the IL-6 mRNA expression level and adding IL-6 to the other independent variables in predicting seizure recurrence.

might be a potential biomarker for prediction of seizure recurrence. Kim et $\mathrm{al}^{54}$ developed a seizure recurrence risk score in the early post-stroke seizure after ischemic stroke patients. This score was based on atrial fibrillation, gender, functional disability, partial seizure type, and cortical lesion with sensitivity of $70.6 \%$ and specificity of $71.0 \%$.

The main limitations of this study included 1) it was a retrospective analysis; 2) there was an unequivocal distribution of the follow-up period; and 3) other unknown variables, able to potentially influence the association between IL-6 and seizure recurrence, might have not been included in the analyses.

Table 4 Distribution Results of the IL-6 mRNA Expression Level $>\mathrm{Q} 3$ in the Case Group and Control Group

\begin{tabular}{|l|l|l|l|}
\hline & Case Group & Control Group & Total \\
\hline$>$ Q3 (5.27) & 72 & 26 & 98 \\
$\leq$ Q3 (5.27) & 33 & 78 & 111 \\
Total & 105 & 104 & 209 \\
\hline
\end{tabular}

\section{Conclusion}

IL-6 level was independently associated with seizure recurrence in patients with the first post-ischemic stroke seizure. Therefore, IL-6 might be a potential biomarker for prediction of seizure recurrence.

\section{Author Contributions}

All authors made substantial contributions to conception and design, acquisition of data, or analysis and interpretation of data; took part in drafting the article or revising it critically for important intellectual content; gave final approval of the version to be published; and agree to be accountable for all aspects of the work.

\section{Disclosure}

The authors report no conflicts of interest in this work.

\section{References}

1. Scheffer IE, Berkovic S, Capovilla G, et al. ILAE Classification of the Epilepsies: position Paper of the ILAE Commission for Classification and Terminology. Epilepsia. 2017;58(4):512-521. doi:10.1111/epi.13709

2. Ngugi AK, Bottomley C, Kleinschmidt I, et al. Estimation of the burden of active and life-time epilepsy: a meta-analytic approach. Epilepsia. 2010;51(5):883-890. doi:10.1111/j.1528-1167.2009.02481.x

3. Balami JS, Chen RL, Grunwald IQ, et al. Neurological complications of acute ischaemic stroke. Lancet Neurol. 2011;10(4):357-371. doi:10.1016/S1474-4422(10)70313-6

4. Hasan TF, Rabinstein AA, Middlebrooks EH, et al. Diagnosis and Management of Acute Ischemic Stroke. Mayo Clin Proc. 2018;93 (4):523-538. doi:10.1016/j.mayocp.2018.02.013

5. Krueger H, Koot J, Hall RE, et al. Prevalence of Individuals Experiencing the Effects of Stroke in Canada: trends and Projections. Stroke. 2015;46 (8):2226-2231. doi:10.1161/STROKEAHA.115.009616

6. Merkler AE, Gialdini G, Lerario MP, et al. Population-Based Assessment of the Long-Term Risk of Seizures in Survivors of Stroke. Stroke. 2018;49 (6):1319-1324. doi:10.1161/STROKEAHA.117.020178

7. Zhao Y, Li X, Zhang K, et al. The Progress of Epilepsy After Stroke. Curr Neuropharmacol. 2018;16(1):71-78. doi:10.2174/1570159X 15666170613083253

8. Karhunen H, Jolkkonen J, Sivenius J, et al. Epileptogenesis after experimental focal cerebral ischemia. Neurochem Res. 2005;30 (12):1529-1542. doi:10.1007/s11064-005-8831-y

9. Back T, Ginsberg MD, Dietrich WD, et al. Induction of spreading depression in the ischemic hemisphere following experimental middle cerebral artery occlusion: effect on infarct morphology. J Cereb Blood Flow Metab. 1996;16(2):202-213. doi:10.1097/00004647199603000-00004

10. Huang CW, Saposnik G, Fang J, et al. Influence of seizures on stroke outcomes: a large multicenter study. Neurology. 2014;82(9):768-776. doi:10.1212/WNL.0000000000000166

11. Burneo JG, Fang J, Saposnik G. Investigators of the Registry of the Canadian Stroke Network. Impact of seizures on morbidity and mortality after stroke: a Canadian multi-centre cohort study. Eur J Neurol. 2010;17(1):52-58. doi:10.1111/j.1468-1331.2009.02739.x

12. Arboix A, García-Eroles L, Massons JB, et al. Predictive factors of early seizures after acute cerebrovascular disease. Stroke. 1997;28 (8):1590-1594. doi:10.1161/01.STR.28.8.1590 
13. van Tuijl JH, van Raak EPM, van Oostenbrugge RJ, et al. Cognition and Quality of Life in Patients With Poststroke Epilepsy: A Case-Control Study. Epilepsy Behav. 2020;104(Pt B):106444. doi:10. 1016/j.yebeh.2019.106444

14. Merlino G, Gigli GL, Bax F, et al. Seizures Do Not Affect Disability and Mortality Outcomes of Stroke: A Population-Based Study. J Clin Med. 2019;8(11):2006. doi:10.3390/jcm8112006

15. Phabphal K, Geater A, Limapichat K, et al. Risk Factors of Recurrent Seizure, Co-Morbidities, and Mortality in New Onset Seizure in Elderly. Seizure. 2013;22(7):577-580. doi:10.1016/j.seizure.2013.04.009

16. Lambertsen KL, Finsen B, Clausen BH. Post-stroke inflammationtarget or tool for therapy? Acta Neuropathol. 2019;137(5):693-714. doi:10.1007/s00401-018-1930-z

17. Wilson S. Task Force members. In response: indications and expectations for neuropsychological assessment in routine epilepsy care: report of the ILAE neuropsychology task force, diagnostic methods commission, 2013-2017. Epilepsia. 2015;56(8):1316-1317. doi:10. 1111/epi.13055

18. Vitaliti G, Pavone P, Marino S, et al. Molecular Mechanism Involved in the Pathogenesis of Early-Onset Epileptic Encephalopathy. Front Mol Neurosci. 2019;12:118. doi:10.3389/fnmol.2019.00118

19. Hongmei Y, Yongping J, Jiyuan L. Interleukin-6 polymorphisms and risk of coronary artery diseases in a Chinese population: a case-control study. Pak J Med Sci. 2016;32(4):880-885. doi:10.12669/pjms.324.9908

20. Ridker PM, Hennekens CH, Buring JE, et al. C-reactive protein and other markers of inflammation in the prediction of cardiovascular disease in women. $N$ Engl $J$ Med. 2000;342(12):836-843. doi:10. 1056/NEJM200003233421202

21. Ridker PM, Rifai N, Stampfer MJ, et al. Plasma concentration of interleukin-6 and the risk of future myocardial infarction among apparently healthy men. Circulation. 2000;101(15):1767-1772. doi:10.1161/01.CIR.101.15.1767

22. Castillo J, Rodríguez I. Biochemical changes and inflammatory response as markers for brain ischaemia: molecular markers of diagnostic utility and prognosis in human clinical practice. Cerebrovasc Dis. 2004;17(Suppl 1):7-18. doi:10.1159/000074791

23. Beamer NB, Coull BM, Clark WM, et al. Interleukin-6 and interleukin-1 receptor antagonist in acute stroke. Ann Neurol. 1995;37(6):800-805. doi:10.1002/ana.410370614

24. Taalab M, Mohammed WF, Helmy MA, et al. Cannabis Influences the Putative Cytokines-Related Pathway of Epilepsy among Egyptian Epileptic Patients. Brain Sci. 2019;9(12):pii: E332. doi:10.3390/ brainsci9120332

25. Uludag IF, Duksal T, Tiftikcioglu BI, et al. IL-1 $\beta$, IL-6 and IL1Ra levels in temporal lobe epilepsy. Seizure. 2015;26:22-25. doi:10.1016/j.seizure.2015.01.009

26. Alapirtti T, Lehtimäki K, Nieminen R, et al. The production of IL-6 in acute epileptic seizure: A video-EEG study. J Neuroimmunol. 2018;316:50-55. doi:10.1016/j.jneuroim.2017.12.008

27. de Vries EE, van den Munckhof B, Braun KP, et al. Inflammatory mediators in human epilepsy: A systematic review and meta-analysis. Neurosci Biobehav Rev. 2016;63:177-190. doi:10.1016/j.neubiorev. 2016.02.007

28. Fisher RS, Acevedo C, Arzimanoglou A, et al. ILAE official report: a practical clinical definition of epilepsy. Epilepsia. 2014;55 (4):475-482. doi:10.1111/epi.12550

29. Chamorro A, Hallenbeck J. The harms and benefits of inflammatory and immune responses in vascular disease. Stroke. 2006;37 (2):291-293. doi:10.1161/01.STR.0000200561.69611.f8

30. McColl BW, Allan SM, Rothwell NJ. Systemic infection, inflammation and acute ischemic stroke. Neuroscience. 2009;158 (3):1049-1061. doi:10.1016/j.neuroscience.2008.08.019

31. Pugazhenthi S, Zhang Y, Bouchard R, et al. Induction of an inflammatory loop by interleukin-1beta and tumor necrosis factor-alpha involves NF-kB and STAT-1 in differentiated human neuroprogenitor cells. PLoS One. 2013;8(7):e69585. doi:10.1371/journal.pone.0069585
32. Ross FM, Allan SM, Rothwell NJ, et al. A dual role for interleukin-1 in LTP in mouse hippocampal slices. J Neuroimmunol. 2003;144 (1-2):61-67. doi:10.1016/j.jneuroim.2003.08.030

33. Del Rey A, Balschun D, Wetzel W, et al. A cytokine network involving brain-borne IL-1beta, IL-1ra, IL-18, IL-6, and TNFalpha operates during long-term potentiation and learning. Brain Behav Immun. 2013;33:15-23. doi:10.1016/j.bbi.2013.05.011

34. Yin P, Li Z, Wang YY, et al. Neonatal immune challenge exacerbates seizure-induced hippocampus-dependent memory impairment in adult rats. Epilepsy Behav. 2013;27(1):9-17. doi:10.1016/j.yebeh.2012.12.015

35. Balosso S, Maroso M, Sanchez-Alavez M, et al. A novel non-transcriptional pathway mediates the proconvulsive effects of interleukin-1beta. Brain. 2008;131(Pt 12):3256-3265. doi:10.1093/ brain/awn271

36. Menon B, Shorvon SD. Ischaemic stroke in adults and epilepsy. Epilepsy Res. 2009;87(1):1-11. doi:10.1016/j.eplepsyres.2009.08.007

37. George P, Punia V, Natteru PA, et al. Predictors of Seizure Recurrence after Acute Symptomatic Seizures in Ischemic Stroke Patients. Neurosci J. 2019;2019:8183921. doi:10.1155/2019/8183921

38. Choi J, Koh S. Role of brain inflammation in epileptogenesis. Yonsei Med J. 2008;49(1):1-18. doi:10.3349/ymj.2008.49.1.1

39. Pera J, Zawadzka M, Kaminska B, et al. Influence of chemical and ischemic preconditioning on cytokine expression after focal brain ischemia. J Neurosci Res. 2004;78(1):132-140. doi:10.1002/ jnr.20232

40. Yamashita T, Sawamoto K, Suzuki S, et al. Blockade of interleukin-6 signaling aggravates ischemic cerebral damage in mice: possible involvement of Stat3 activation in the protection of neurons. $J$ Neurochem. 2005;94(2):459-468. doi:10.1111/j.1471-4159.2005.03227.x

41. Alyu F, Dikmen M. Inflammatory aspects of epileptogenesis: contribution of molecular inflammatory mechanisms. Acta Neuropsychiatr. 2017;29(1):1-16. doi:10.1017/neu.2016.47

42. Gruol DL.IL-6 regulation of synaptic function in the CNS. Neuropharmacology. $\quad 2015 ; 96(\mathrm{Pt} \quad$ A):42-54. doi:10.1016/j. neuropharm.2014.10.023

43. Erta M, Quintana A, Hidalgo J. Interleukin-6, a major cytokine in the central nervous system. Int J Biol Sci. 2012;8(9):1254-1266. doi:10.7150/ijbs.4679

44. Fang XX, Jiang XL, Han XH, et al. Neuroprotection of interleukin-6 against NMDA-induced neurotoxicity is mediated by JAK/STAT3, MAPK/ ERK, and PI3K/AKT signaling pathways. Cell Mol Neurobiol. 2013;33(2):241-251. doi:10.1007/s10571-012-9891-6

45. Wang X, Ma C, Liu CY, et al. Neuronal NMDAR Currents of the Hippocampus and Learning Performance in Autoimmune AntiNMDAR Encephalitis and Involvement of TNF- $\alpha$ and IL-6. Front Neurol. 2019;10:684. doi:10.3389/fneur.2019.00684

46. Levin SG, Godukhin OV. Modulating effect of cytokines on mechanisms of synaptic plasticity in the brain. Biochemistry (Mosc). 2017;82 (3):264-274. doi:10.1134/S000629791703004X

47. Sanchez-Munoz F, Dominguez-Lopez A, Yamamoto-Furusho JK. Role of cytokines in inflammatory bowel disease. World J Gastroenterol. 2008;14(27):4280-4288. doi:10.3748/wjg.14.4280

48. Yarlagadda A, Alfson E, Clayton AH. The blood brain barrier and the role of cytokines in neuropsychiatry. Psychiatry. 2009;6(11):18-22.

49. Vezzani A, French J, Bartfai T, et al. The role of inflammation in epilepsy. Nat Rev Neurol. 2011;7(1):31-40. doi:10.1038/ nrneurol.2010.178

50. Ho YH, Lin YT, Wu CW, et al. Peripheral inflammation increases seizure susceptibility via the induction of neuroinflammation and oxidative stress in the hippocampus. J Biomed Sci. 2015;22:46. doi:10.1186/s12929-015-0157-8

51. Samuelsson A, Jennische E, Hansson $H$, et al. $\operatorname{Pren}_{A} t_{A} 1$ exposure to interleukin-6 results in $\operatorname{infl}_{\mathrm{A}} \mathrm{mm}_{\mathrm{A}}$ tory neurodegener ${ }_{\mathrm{A}}$ tion in hippoc $\mathrm{A}_{\mathrm{A}}$ mpus with $\mathrm{NMD}_{\mathrm{A}}</$ sub $>/ \mathrm{G}_{\mathrm{A}} \mathrm{B}_{\mathrm{A} \text { A }}$ dysregul $\mathrm{A}_{\mathrm{A}}$ tion ${ }_{\mathrm{A}}$ nd $\mathrm{imp}_{\mathrm{A}}$ ired $\mathrm{sp}_{\mathrm{A}}$ $\mathrm{ti}_{\mathrm{A}} 1$ le $\mathrm{e}_{\mathrm{A}}$ rning. Am J Physiol Regul Integr Comp Physiol. 2005;290(5): R1345-1356. doi:10.1152/ajpregu.00268.2005 
52. Pineda E, Shin D, You SJ, et al. Maternal immune activation promotes hippocampal kindling epileptogenesis in mice. Ann Neurol. 2013;74(1):11-19. doi:10.1002/ana.23898

53. Fu MM, Wang YZ, Li YK, et al. Recurrence after the first epileptic seizure in patients with stroke: an analysis of risk factors. Chin J Cerebrovasc Dis. 2018;15(8):398-403.

54. Kim HJ, Park KD, Choi KG, et al. Clinical Predictors of Seizure Recurrence After the First Post-Ischemic Stroke Seizure. BMC Neurol. 2016;16(1):212. doi:10.1186/s12883-016-0729-6

55. Petrides G, Braga RJ, Fink M, et al. Seizure threshold in a large sample: implications for stimulus dosing strategies in bilateral electroconvulsive therapy: a report from CORE. J ECT. 2009;25 (4):232-237. doi:10.1097/YCT.0b013e31819c76ff
56. Tanaka T, Yamagami H, Ihara M, et al. Seizure outcomes and predictors of recurrent post-stroke seizure: a retrospective observational cohort study. PLoS One. 2015;10(8):e0136200. doi:10.1371/journal. pone. 0136200

57. Chen TC, Chen YY, Cheng PY, et al. The incidence rate of post-stroke epilepsy: a 5-year follow-up study in Taiwan. Epilepsy Res. 2012;102(3):188-194. doi:10.1016/j.eplepsy res.2012.06.003
Neuropsychiatric Disease and Treatment

\section{Publish your work in this journal}

Neuropsychiatric Disease and Treatment is an international, peerreviewed journal of clinical therapeutics and pharmacology focusing on concise rapid reporting of clinical or pre-clinical studies on a range of neuropsychiatric and neurological disorders. This journal is indexed on PubMed Central, the 'PsycINFO' database and CAS, and
Dovepress

is the official journal of The International Neuropsychiatric Association (INA). The manuscript management system is completely online and includes a very quick and fair peer-review system, which is all easy to use. Visit http://www.dovepress.com/testimonials.php to read real quotes from published authors.

Submit your manuscript here: https://www.dovepress.com/neuropsychiatric-disease-and-treatment-journal 